\title{
Nutritional status of schoolchildren in an urban area of Sri Lanka
}

\author{
VP Wickramasinghe ${ }^{1}$, SP Lamabadusuriya ${ }^{2}$, N Atapattu ${ }^{3}$, G Sathyadas ${ }^{1}$, S Kuruparanantha ${ }^{3}$ and \\ P Karunarathne ${ }^{3}$
}

(Index words: Obesity, overweight, schoolchildren, undernutrition)

\begin{abstract}
Background As in many other Asian countries, Sri Lanka is in the phase of a rapid demographic, nutritional and epidemiological transition. As a result dietary habits and lifestyle are changing. These have led to new health problems in the region. Childhood overweight and obesity are examples of such problems.
\end{abstract}

Objective To provide information on the nutritional status of 8-12 years old schoolchildren in an urban area of Sri Lanka.

Subjects and methods Seven schools situated in the city of Colombo were randomly selected. They showed a fair representation of children of all social levels. Fifty students from each grade (years 4, 5, 6, 7) of each school were randomly selected. Their height was measured using a stadiometer to the closest $0.1 \mathrm{~cm}$ and weight measured using an electronic weighing scale (Seca®, France) to the closest $100 \mathrm{~g}$. Calibration was checked with a standard weight at each 25 measurements. Information regarding behaviour, feeding practices and socioeconomic factors were obtained by a questionnaire filled by the parent or the guardian. To define obesity and overweight, sex and age specific body mass index (BMI) criteria recommended by the International Obesity Task Force (IOTF) were used. The age and sex specific BMI 5th percentile from revised NCHS (2000) growth charts were used to define thinness. Weight and height $Z$ score of less than -2 from the median of height for age and weight for age derived using the ANTHRO software (CDC, USA) were used to define stunting and underweight respectively. Data were analysed using Epilnfo 2000 (CDC, USA) computer package.

Results Anthropometric data of 1224 children (48\% boys), and feeding practices and behaviour pattern data of 1102 children (44\% boys) were analysed. Obesity prevalence among boys (4.3\%) was higher than in girls (3.1\%). The prevalence of thinness was $24.7 \%$ in boys and $23.1 \%$ in girls. $5.1 \%$ of boys and $5.2 \%$ of girls were stunted. $7.0 \%$ of boys and $6.8 \%$ of girls were underweight. $66 \%$ of obese children and $43.5 \%$ of overweight children belonged to high-income category (monthly family income more than Rs. 20 000). Apart from family income, behaviour patterns did not significantly influence the nutritional status.

Conclusions Although the data are not representative of the entire country, nutritional transition is evident in the city of Colombo. Obesity and overweight in older children are some emerging nutritional problems that may be the consequence of emerging patterns of the lifestyle and diet in response to social and cultural changes.

\section{Introduction}

Nutritional transition occurring in Asian countries is one facet of a more general demographic, epidemiological and nutritional transition occurring with the socioeconomic development and urbanisation. The nutritional transition has shifted people from a relatively stereotype diet, based on indigenous staple grains, starchy roots and legumes, fruits and vegetables, with smaller amounts of foods of animal origin, towards more varied diets that include more processed and refined food, more foods of animal origin and more added sugar, fat and preservatives [1].

With the changes in the socioeconomic status the lifestyle of adults as well as children change. The eating habits are influenced by lack of time to prepare meals at home, and the availability of fast-food outlets and food vending machines. The amount of physical activity is influenced by the competition for higher grades at school, compelling children to attend extra classes. Television viewing, involvement in computer games and the increased use of private transport have contributed towards a lifestyle with low physical activity.

In spite of the economic advances in the region, undernutrition remains a significant problem in many Asian countries. It was estimated that in 2000, 34\% Asian preschool children were stunted and $29 \%$ were underweight [2]. In 1995, it was estimated that $3.3 \%$ were overweight in developing countries of the world and $2.9 \%$ in Asia [2]. The overall prevalence of wasting recorded in developing countries is high $(10.4 \%)$ [3]. Socioeconomic changes that occurred with the open economy gave rise to overweight and obesity while the prevalence of stunting, underweight and wasting did not change much. In 1995, diet related chronic diseases accounted for $18.3 \%$ of all deaths in Sri Lanka [2]. It is predicted that dietary factors, especially overweight, will account for $18 \%$ to $40 \%$ of diet related chronic diseases and $20.9 \%$ of all deaths by 2025 [1].

Although data on nutritional status of preschool children are available [4], data on schoolchildren are

\footnotetext{
${ }^{1}$ Lecturer, ${ }^{2}$ Senior Professor, Department of Paediatrics, Faculty of Medicine, University of Colombo, Sri Lanka; ${ }^{3}$ House Officer, Professorial Paediatrics Unit, Lady Ridgeway Hospital for Children, Colombo, Sri Lanka.

Correspondence: VPW, e-mail: <pujithaw@yahoo.com> (Competing interests: none declared). Received 20 December 2003 and revised version accepted 26 June 2004.
} 
limited for this country as well as for other countries in the world [3]. Undernutrition has been a major problem in this age group and now overweight and obesity are emerging as new public health problems. As data are lacking for this category we did a pilot project to investigate the nutritional status of schoolchildren in Colombo. Assumably, the nutritional status would have been affected by the socioeconomic changes that occurred over the last 2 to 3 decades.

\section{Subjects and methods}

Seven schools in Colombo were randomly selected. These schools showed a fair representation of children of all social levels. Students of years 4, 5, 6 and 7 were included. Fifty students from each grade of each school were randomly selected and recruited to the study. The students were counselled about the purpose of the study and withdrawals were allowed. The study was carried out in October 2002.

Medical officers performed the anthropometric measurements. The height was measured using a stadiometer. The children were positioned with heels, buttocks, back of the chest and back of head touching the vertical plane of the stadiometer and the head held in the Frankfurt horizontal plane. All height measurements were done by one examiner and to the closest $0.1 \mathrm{~cm}$. Weight was measured using an electronic weighing scale (Seca ${ }^{\circledR}$, France) to the closest $100 \mathrm{~g}$. The weighing scale was checked with a standard weight after every 25 measurements. Medical assessment was done in all children who participated in the study. Information regarding behaviour, feeding practices and socioeconomic factors were obtained by a questionnaire filled by the parent or the guardian.

To define obesity and overweight, we used sex and age specific body mass index (BMI) cut off values recommended by the International Obesity Task Force (IOTF) [5]. Since all children could not be analysed for their weight for height, because the heights of the sample ranged well beyond the NCHS references for weight for height, wasting was not calculated but thinness was assessed. Thinness was defined as BMI below 5th percentile for age of the revised NCHS sex and age reference charts [6]. Children were considered underweight or stunted if their weight or height $\mathrm{Z}$ scores were less than 2SD of the NCHS median for weight for age and height for age respectively. $\mathrm{Z}$ scores were calculated using the ANTHRO (CDC, USA) software. Data was analysed using EpiInfo 2000 (CDC, USA) software.

\section{Results}

A total of 1266 children were recruited to the study but only $1224(96.7 \%)$ were included in the anthropometric analyses. Of these, $48 \%$ of the children were boys. The children belonged to three types of schools, private, public national and public non-national-349 (28.5\%) were from private schools, $543(44.3 \%)$ from public national schools, and $332(27.2 \%)$ from public non-national schools. Table 1 shows the age and sex distribution of the children with the mean height, weight and BMI for each category.

Eight- and 9-year old boys were slightly taller than their female counterparts but at the age of 10-12 years girls were taller than the boys, probably due to early onset of pubertal growth spurt in the former. Eight- and 9-year old boys were slightly heavier than the girls of the same age on average, but in 10-12-year olds this had reversed. The mean $\mathrm{Z}$ score for both height and weight was negative for all age groups. The 11- and 12-year old girls had a higher BMI than the boys of the same age group.

Tables 2 and 3 show the mean height, weight and BMI distribution according to the age, sex and school type. On average, boys from private schools were taller than their counterparts from public schools except for 9-year old boys from public national schools. Boys from private schools were always heavier, followed by boys from public national schools. The BMI of the boys of private schools were higher in every age group. The anthropometric indices of girls did not follow the same pattern. Eight- and 10-year

Table 1. Mean height, weight and BMI of school children according to age and sex

\begin{tabular}{|c|c|c|c|c|c|c|}
\hline \multirow{2}{*}{$\begin{array}{l}\text { Age } \\
\text { (years) }\end{array}$} & \multirow[b]{2}{*}{$N$} & \multicolumn{2}{|c|}{ Height } & \multicolumn{2}{|c|}{ Weight } & \multirow{2}{*}{$\frac{B M I}{M e a n \pm S D}$} \\
\hline & & $\overline{M e a n} \pm S D$ & Mean Z score $\pm S D$ & Mean $\pm S D$ & Mean Z score $\pm S D$ & \\
\hline \multicolumn{7}{|l|}{ Male } \\
\hline 8 & 83 & $129.7 \pm 6.72$ & $-0.15 \pm 1.26$ & $26.9 \pm 8.09$ & $-0.34 \pm 1.72$ & $15.7 \pm 3.92$ \\
\hline 9 & 135 & $133.8 \pm 6.58$ & $-0.26 \pm 1.09$ & $29.9 \pm 7.47$ & $-0.19 \pm 1.30$ & $16.5 \pm 3.01$ \\
\hline 10 & 140 & $138.2 \pm 7.64$ & $-0.27 \pm 1.21$ & $32.3 \pm 8.71$ & $-0.40 \pm 1.28$ & $16.7 \pm 3.20$ \\
\hline 11 & 142 & $142.2 \pm 7.63$ & $-0.47 \pm 1.07$ & $34.8 \pm 9.42$ & $-0.54 \pm 1.27$ & $17.1 \pm 3.53$ \\
\hline 12 & 88 & $147.1 \pm 8.80$ & $-0.56 \pm 0.86$ & $39.1 \pm 10.44$ & $-0.50 \pm 1.11$ & $17.6 \pm 3.43$ \\
\hline \multicolumn{7}{|l|}{ Female } \\
\hline 8 & 77 & $127.9 \pm 6.13$ & $-0.33 \pm 1.25$ & $25.3 \pm 6.76$ & $-0.54 \pm 1.36$ & $15.3 \pm 2.15$ \\
\hline 9 & 170 & $133.2 \pm 6.57$ & $-0.28 \pm 0.95$ & $28.4 \pm 6.70$ & $-0.59 \pm 1.26$ & $15.8 \pm 2.86$ \\
\hline 10 & 131 & $138.4 \pm 8.66$ & $-0.44 \pm 1.23$ & $32.6 \pm 8.39$ & $-0.64 \pm 1.95$ & $16.5 \pm 3.19$ \\
\hline 11 & 175 & $145.0 \pm 8.20$ & $-0.42 \pm 1.17$ & $37.9 \pm 10.13$ & $-0.38 \pm 1.20$ & $17.8 \pm 3.86$ \\
\hline 12 & 83 & $150.8 \pm 7.83$ & $-0.26 \pm 1.14$ & $41.9 \pm 11.10$ & $-0.25 \pm 1.29$ & $18.3 \pm 3.67$ \\
\hline
\end{tabular}


Table 2. Mean height, weight and BMI of schoolboys according to age and type of school

\begin{tabular}{|c|c|c|c|c|c|c|c|}
\hline \multirow{2}{*}{$\begin{array}{l}\text { Age } \\
\text { (years) }\end{array}$} & \multirow[t]{2}{*}{ Type of school } & \multirow[t]{2}{*}{$N$} & \multicolumn{2}{|c|}{ Height } & \multicolumn{2}{|c|}{ Weight } & \multirow{2}{*}{$\frac{B M I}{M e a n \pm S D}$} \\
\hline & & & Mean $\pm S D$ & $Z \pm S D$ & Mean $\pm S D$ & $Z \pm S D$ & \\
\hline \multirow[t]{3}{*}{8} & Private & 27 & $131.2 \pm 4.95$ & $0.28 \pm 0.93$ & $29.6 \pm 6.98$ & $0.42 \pm 1.49$ & $17.0 \pm 3.24$ \\
\hline & Public-National & 38 & $130.6 \pm 7.53$ & $-0.06 \pm 1.35$ & $26.9 \pm 9.45$ & $-0.45 \pm 1.92$ & $15.6 \pm 4.02$ \\
\hline & -Non-national & 18 & $125.4 \pm 5.54$ & $-1.01 \pm 1.09$ & $23.1 \pm 4.24$ & $-1.24 \pm 1.03$ & $13.8 \pm 4.05$ \\
\hline \multirow[t]{3}{*}{9} & Private & 29 & $132.6 \pm 5.00$ & $-0.39 \pm 0.87$ & $30.2 \pm 6.17$ & $-0.15 \pm 1.18$ & $17.2 \pm 3.00$ \\
\hline & Public-National & 83 & $134.1 \pm 7.02$ & $0.11 \pm 1.14$ & $31.0 \pm 8.21$ & $-0.02 \pm 1.36$ & $16.7 \pm 3.17$ \\
\hline & -Non-national & 23 & $130.4 \pm 6.16$ & $-0.70 \pm 1.10$ & $25.8 \pm 4.20$ & $-0.92 \pm 0.97$ & $15.0 \pm 1.76$ \\
\hline \multirow[t]{3}{*}{10} & Private & 29 & $139.1 \pm 8.43$ & $-0.12 \pm 1.35$ & $35.8 \pm 11.30$ & $0.06 \pm 1.44$ & $18.0 \pm 3.61$ \\
\hline & Public-National & 79 & $138.6 \pm 6.97$ & $-0.17 \pm 1.08$ & $32.5 \pm 8.40$ & $-0.32 \pm 1.27$ & $16.8 \pm 3.23$ \\
\hline & -Non-national & 32 & $136.8 \pm 8.36$ & $-0.58 \pm 1.69$ & $28.8 \pm 5.16$ & $-1.03 \pm 0.92$ & $15.2 \pm 2.08$ \\
\hline \multirow[t]{3}{*}{11} & Private & 27 & $145.7 \pm 9.32$ & $-0.03 \pm 1.24$ & $38.9 \pm 10.50$ & $-0.02 \pm 1.36$ & $18.3 \pm 4.34$ \\
\hline & Public-National & 78 & $143.1 \pm 6.50$ & $-0.36 \pm 0.89$ & $35.4 \pm 9.41$ & $-0.44 \pm 1.26$ & $17.1 \pm 3.55$ \\
\hline & -Non-national & 37 & $138.4 \pm 7.09$ & $-1.02 \pm 1.07$ & $31.2 \pm 7.39$ & $-1.07 \pm 1.06$ & $16.2 \pm 2.55$ \\
\hline \multirow[t]{3}{*}{12} & Private & 28 & $149.0 \pm 1153$ & $-0.44 \pm 0.70$ & $44.0 \pm 11.92$ & $-0.04 \pm 1.03$ & $19.7 \pm 3.91$ \\
\hline & Public-National & 45 & $146.5 \pm 7.72$ & $-0.56 \pm 0.99$ & $36.9 \pm 8.37$ & $-0.68 \pm 1.04$ & $17.0 \pm 2.73$ \\
\hline & -Non-national & 15 & $144.4 \pm 4.42$ & $-0.85 \pm 0.60$ & $35.5 \pm 10.46$ & $-0.88 \pm 1.26$ & $17.1 \pm 4.65$ \\
\hline
\end{tabular}

Table 3. Mean height, weight and BMI of schoolgirls according to age and type of school

\begin{tabular}{|c|c|c|c|c|c|c|c|}
\hline \multirow{2}{*}{$\begin{array}{l}\text { Age } \\
\text { (years) }\end{array}$} & \multirow[t]{2}{*}{ Type of school } & \multirow[t]{2}{*}{$N$} & \multicolumn{2}{|c|}{ Height } & \multicolumn{2}{|c|}{ Weight } & \multirow{2}{*}{$\frac{B M I}{\text { Mean } \pm S D}$} \\
\hline & & & $\overline{M e a n} \pm S D$ & $Z \pm S D$ & $\overline{M e a n} \pm S D$ & $Z \pm S D$ & \\
\hline \multirow[t]{3}{*}{8} & Private & 36 & $129.5 \pm 6.13$ & $0.06 \pm 1.48$ & $25.8 \pm 8.37$ & $-0.32 \pm 1.66$ & $15.3 \pm 3.48$ \\
\hline & Public-National & 17 & $123.8 \pm 5.50$ & $-1.09 \pm 0.86$ & $25.3 \pm 6.09$ & $-0.67 \pm 1.23$ & $15.9 \pm 2.57$ \\
\hline & -Non-national & 24 & $128.4 \pm 5.37$ & $-0.37 \pm 0.79$ & $24.7 \pm 4.11$ & $-0.79 \pm 0.85$ & $14.8 \pm 1.86$ \\
\hline \multirow[t]{3}{*}{9} & Private & 60 & $133.4 \pm 6.55$ & $-0.31 \pm 0.91$ & $29.3 \pm 6.93$ & $-0.53 \pm 1.46$ & $16.4 \pm 3.28$ \\
\hline & Public-National & 51 & $134.9 \pm 6.69$ & $0.01 \pm 1.03$ & $30.1 \pm 6.78$ & $-0.17 \pm 1.16$ & $16.4 \pm 2.56$ \\
\hline & -Non-national & 59 & $131.8 \pm 6.26$ & $-0.48 \pm 0.88$ & $26.1 \pm 5.90$ & $-0.93 \pm 1.03$ & $14.9 \pm 2.4$ \\
\hline \multirow[t]{3}{*}{10} & Private & 31 & $141.5 \pm 8.30$ & $-0.05 \pm 1.14$ & $33.3 \pm 8.70$ & $-0.47 \pm 1.16$ & $16.9 \pm 2.99$ \\
\hline & Public-National & 56 & $139.1 \pm 8.82$ & $-0.33 \pm 1.28$ & $34.9 \pm 8.58$ & $-0.47 \pm 2.69$ & $17.4 \pm 3.48$ \\
\hline & -Non-national & 44 & $135.1 \pm 7.75$ & $-0.87 \pm 1.09$ & $34.9 \pm 6.70$ & $-0.99 \pm 0.92$ & $15.5 \pm 2.65$ \\
\hline \multirow[t]{3}{*}{11} & Private & 53 & $145.5 \pm 8.07$ & $-0.38 \pm 1.17$ & $38.7 \pm 8.10$ & $-0.23 \pm 0.97$ & $18.3 \pm 3.89$ \\
\hline & Public-National & 67 & $146.7 \pm 7.49$ & $-0.19 \pm 1.09$ & $39.2 \pm 10.71$ & $-0.22 \pm 1.25$ & $18.2 \pm 3.78$ \\
\hline & -Non-national & 55 & $142.3 \pm 8.81$ & $-0.81 \pm 1.19$ & $35.1 \pm 10.60$ & $-0.74 \pm 1.25$ & $17.0 \pm 3.87$ \\
\hline \multirow[t]{3}{*}{12} & Private & 29 & $150.6 \pm 7.83$ & $-0.35 \pm 1.12$ & $43.5 \pm 14.30$ & $-0.13 \pm 1.50$ & $19.1 \pm 4.90$ \\
\hline & Public-National & 29 & $150.2 \pm 7.23$ & $-0.38 \pm 1.05$ & $41.1 \pm 9.05$ & $-0.32 \pm 1.10$ & $17.7 \pm 2.69$ \\
\hline & -Non-national & 25 & $151.0 \pm 5.47$ & $-0.01 \pm 1.29$ & $41.6 \pm 10.01$ & $-0.28 \pm 1.16$ & $17.4 \pm 2.33$ \\
\hline
\end{tabular}

old girls from private schools were taller than girls from public schools. Nine- and 11-year old girls from public national schools were the tallest. Twelve-year olds from public non-national schools were slightly taller than the others of the same age with a low standard deviation.

Girls from private and public national schools were always heavier than the girls from public non-national schools and the BMI of the latter was always lower than the other two groups.

The prevalence of undernutrition was assessed on the basis of three indices: height for age, weight for age and BMI for age, using the descriptive terms of stunting, underweight and thinness respectively (Table 4). About $5 \%$ of the population of each sex was stunted. The prevalence of underweight was high $(7 \%$ of boys and $6.8 \%$ of girls) and younger age groups were more affected. A $24.7 \%$ boys and $23.1 \%$ girls were considered to be thin. Undernutrition was marked in public non-national school children. Undernutrition in public national schools was more prevalent than in private school children but much better than children from public non-national schools. This was the case in both sexes (Table 5).

Table 4 shows the prevalence of obesity and overweight based on sex and age. The prevalence of obesity was higher among boys in all ages except for 11year old girls. Overweight prevalence also showed a similar pattern of distribution except in the case of 11and 12-year old girls. The prevalence of obesity was more among the private school girls $(4.8 \%)$ and boys $(8.6 \%)$ compared to their counterparts in public schools. Only $0.8 \%$ girls and $1.9 \%$ boys from public non-national schools were obese. The prevalence of obesity among public national schools is in between the other two categories of schoolchildren (Table 5). 
Table 4. Prevalence of over- and undernutrition among schoolchildren according to age and sex

\begin{tabular}{|c|c|c|c|c|c|c|}
\hline $\begin{array}{l}\text { Age } \\
\text { (years) } \\
\end{array}$ & $N$ & $\begin{array}{c}\text { Obesity } \\
(\%)\end{array}$ & $\begin{array}{c}\text { Overweight } \\
(\%)\end{array}$ & $\begin{array}{c}\text { Thinness } \\
(\%)\end{array}$ & $\begin{array}{c}\text { Stunting } \\
(\%)\end{array}$ & $\begin{array}{c}\text { Underweight } \\
(\%)\end{array}$ \\
\hline \multicolumn{7}{|l|}{ Male } \\
\hline 8 & 83 & 9.6 & 9.6 & 29.0 & 2.4 & 14.5 \\
\hline 9 & 135 & 3.7 & 14.1 & 22.2 & 5.2 & 6.6 \\
\hline 10 & 140 & 2.2 & 15.8 & 25.9 & 6.0 & 2.2 \\
\hline 11 & 142 & 3.5 & 9.2 & 28.2 & 5.6 & 7.7 \\
\hline 12 & 88 & 4.5 & 3.4 & 17.0 & 5.7 & 6.8 \\
\hline Total & 588 & & & & & \\
\hline \multicolumn{7}{|l|}{ Female } \\
\hline 8 & 77 & 2.6 & 5.2 & 27.3 & 5.2 & 9.1 \\
\hline 9 & 170 & 3.0 & 7.6 & 26.5 & 1.8 & 7.1 \\
\hline 10 & 131 & 2.3 & 7.6 & 26.5 & 6.9 & 7.4 \\
\hline 11 & 175 & 4.6 & 16.6 & 21.1 & 7.4 & 7.4 \\
\hline 12 & 83 & 2.4 & 15.6 & 15.6 & 4.8 & 6.0 \\
\hline Total & 636 & & & & & \\
\hline
\end{tabular}

Table 5. Prevalence of under- and overnutrition among schoolchildren according to the type of school

\begin{tabular}{lcccccc}
\hline Type of school & $\mathrm{N}$ & $\begin{array}{c}\text { Obesity } \\
(\%)\end{array}$ & $\begin{array}{c}\text { Overweight } \\
(\%)\end{array}$ & $\begin{array}{c}\text { Thinness } \\
(\%)\end{array}$ & $\begin{array}{c}\text { Stunting } \\
(\%)\end{array}$ & $\begin{array}{c}\text { Underweight } \\
(\%)\end{array}$ \\
\hline Private & 349 & 6.3 & 13.2 & 17.5 & 2.6 & 4.3 \\
Public-National & 543 & 3.3 & 13.5 & 23.0 & 7.8 & 7.4 \\
Public Non-National & 332 & 1.5 & 6.0 & 31.0 & 9.3 & 11.1 \\
\hline
\end{tabular}

Data regarding physical activity and dietary habits were available only for $1102(87 \%)$ children. Sixty two per cent had breakfast prepared at home whereas $7.2 \%$ bought breakfast prepared by an outside source on all 5 school days of the week. About $75 \%$ had a home prepared lunch and dinner on all days of the week, and the remainder took meals prepared outside on variable number of days. The consumption of vegetables was satisfactory. However, the intake of fruits was low and a majority had less than three weekly servings. Milk and eggs were the main source of animal protein.

A majority of children in this study spent less than $2 \mathrm{~h}$ daily watching television during the weekdays. However, $49.3 \%$ spent more than $4 \mathrm{~h}$ daily in viewing television during the weekend. Time spent on outdoor physical activity was low. A $68.2 \%$ and $88.4 \%$ spent less than $2 \mathrm{~h}$ a week on outdoor physical activity during weekends and weekdays respectively. A significant number of children of all age groups attended tuition classes. Sixty three per cent to $68 \%$ of children of each age group attended tuition classes during weekdays, and $55 \%$ to $64 \%$ did so during weekends. The percentage rose with the age. Comparison between schools did not show a significant difference. Computer games were not a popular recreational activity among this group of children. Although the children showed a sedentary lifestyle, time spent on watching television $(\mathrm{r}=0.00)$ and outdoor physical activity $(\mathrm{r}=0.00)$ did not show a relationship to BMI of these children. The only socioeconomic and behaviour variable that showed a relationship to BMI was the income of the family $(r=0.4, p<0.001)$. The differences that existed in the nutritional status between children of different types of schools were probably a reflection of the economic status of the family.

The nutritional status of children from private schools was better than those who were coming from public schools. Children from public national schools had a better nutritional status compared to children from public non-national schools. Children in private and public national schools came from a more affluent section of the society (data not shown). More than $69 \%$ of children from private schools and more than $43 \%$ of children from public national schools had a monthly family income of more than Rs 20 000. In contrast, more than $64 \%$ of the children in public non-national schools had a family income of less than Rs 10000 per month, and almost half of them had a monthly income less than Rs 5000 .

\section{Discussion}

The underfed still outnumber the overfed in the developing world among Asian, African and Latin American populations. The economic development that has occurred in these regions during the last two decades has led to more division in the society with increased inequality. Obesity and overweight are new nutrition problems emerging all over the world, including developing countries.

An understanding and awareness of the heavy burden of malnutrition and disease among schoolchildren is growing [3]. Overweight and obesity are becoming increasingly prevalent in low-income countries where improvement in socioeconomic conditions and rapid 
urbanisation are causing a "nutritional transition". A rapid shift in the composition of diet (high fat), reduced activity and a consequent shift in the body composition characterise this transition.

The data shows that the nutritional status is largely influenced by the socioeconomic status. The students attending private schools are with a good socioeconomic status and their nutritional status had always been better than the students attending public schools. Those of national schools were well above their counterparts from non-national schools. National schools are a sector of public schools which have more facilities. Gaining admission to such schools is highly competitive, and mostly parents need to be from higher socioeconomic groups.

The mean $\mathrm{Z}$ score for height and weight closer to zero, for the children from private schools denoting the nutritional status of the children from higher socioeconomic status, matches with the NCHS standards.

Irrespective of the type of school or socioeconomic state, the feeding habits and behaviour patterns were not acceptable. Children in this study showed a more sedentary lifestyle with less time spent on physical activity and more time spent on watching television and attending tuition classes. Although the consumption of vegetables, eggs and milk was satisfactory, the consumption of fruits, fish and meat was low, perhaps it may be a reflection of the economic strength of the family.

With economic advances, a nutrition transition is occurring in our country. As a result, overweight and obesity prevalence is on the rise. This emerging public health problem may give rise to many diet related problems in the future. As economic advantages are not evenly distributed, undernutrition still prevails in the country to a significant degree.

\section{References}

1. Popkin FM, Horton SH, Kim S. The nutrition transition and prevention of diet related diseases in Asia and the pacific: Executive summary. Food and Nutrition Bulletin 2001; 22: 3-4.

2. Tee ES. Priority nutritional concerns in Asia. Food and Nutrition Bulletin 2002; 23: 345-8.

3. Drake L, Maier C, Jukes M, Patrikios A, Bundy D, et al. School age children: their nutrition and health. SCN (Standing Committee on Nutrition) News; United Nations System 2002; 25: 4-30.

4. Sri Lanka Demographic and Health Survey 2000. Department of Census and Statistics, Ministry of Health, Nutrition and Welfare. Colombo, 2000: 199-202.

5. Cole TJ, Bellizzi MC, Flegal KM, Dietz WH. Establishing a standard definition for child overweight and obesity worldwide: international survey. British Medical Journal 2000; 320: 1240-3.

6. CDC growth charts: United States; revised. Advance Data, U.S. Department of Health and Human Services, CDC, NCHS. 2000; 314: 1-28. 